\title{
Accidental Exposure to Blood: Case Reporting and Management of Healthcare workers in the Biyem-assi District Hospital in 2016
}

\author{
Article by Judith Maka ${ }^{1}$, Vladimir Pente Yamou ${ }^{2}$, Joseph Essama ${ }^{3}$ \\ ${ }^{1}$ Ph.D, Public Health, Chief of the International immunization center of Yaoundé \\ ${ }^{2} \mathrm{MPH}$, Epidemiology \\ ${ }^{3}$ Director of the Biyem-assi District Hospital \\ E-mail: Judithmani70@hotmail.com ${ }^{1}$,vladpent@yahoo.fr ${ }^{2}$, \\ kejalessama@yahoo.com ${ }^{3}$
}

\begin{abstract}
Introduction: Accidental Exposure to Blood and body fluids (AEB) is one of the most important risks among Healthcare workers $(\mathrm{HCW})$, and is less reported in some settings. They are exposed to many blood borne pathogens including HIV, Hepatitis C virus, and Hepatitis B virus. The objective of this study was to assess the quality of the case reporting, the post-exposure management and to address some suggestions for the HCW protection in the Biyem-assi District Hospital (BDH).

Method: We obtained an administrative authorization, we conducted a cross sectional hospitalbased study from $6^{\text {th }}$ September to $20^{\text {th }}$ October 2016. We used the register of all the reported Accidental injuries, a convenience sampling in the different $H C W$ groups in contact with patients, and addressed a questionnaire to assess their knowledge, their immunization status against HBV. We performed a descriptive analysis of data using Epi info version 7.1.1.14.

Results: There is a good knowledge of the definition of the AEB. Only injuries with the HIV positive patients were reported, no hepatitis test and Anti-Hbs titer were performed on the victims. Less information is known about the outcome after the post-exposure prophylaxis, $48.84 \%$ of the HCW have not received a vaccination against Hepatitis $B .83 .72 \%$ of the participants do not have any Health insurance.

Conclusion: $A E B$ is less reported in the BDH. $48.84 \%$ of $H C W$ are not vaccinated against the $H B V$. There is a need for Sensitization for a complete case-reporting, follow-up after injuries; Strong regulations for a mandatory immunization among $\mathrm{HCW}$.
\end{abstract}

Keywords: Accidental- Exposure, Healthcare -workers, HIV, HBV, HCV.

\section{Introduction}

Accidental Exposure to Blood and other fluids (AEB) is the unintended contact with blood and or body fluids mixed with blood, during a medical intervention (World Health Organization, 2012). The main blood borne infectious diseases that exposes Health care personnel is the Hepatitis B (6-30\%), followed by the hepatitis $\mathrm{C}(1.8 \%)$ and $0.3 \%$ for HIV. The assessment and treatment of the consequences of such accidents is a huge burden on society in terms of the costs of treatment and absence from work, as well as of distress and anxiety at work. Preventive measures have been put in place to reduce the transmission of many pathogens (Streefland, 2001). Also, there are many recommendations for the management of healthcare workers occupationally exposed to hepatitis $\mathrm{B}$ and hepatitis $\mathrm{C}$ viruses and HIV. These recommendations include some post exposition prophylaxis to reduce the transmission of these viruses to the healthcare personnel (Puro et al., 2005).

Managing the Accidental exposure to patient's blood is a big challenge; from May 2012 to august 2012, Jain et al. (2016) conducted a descriptive analytical cross sectional study to evaluate the Knowledge, practice and attitude (PEP) and Hepatitis B virus immunization among 50 faculty and 115 under graduated students. They found a high prevalence of these accidental exposure $(49.7 \%)$ and more than half of these respondents did not report the injury (Jain, Sabharwal, \& Srivastava, 2016). Healthcare workers are less trained about the waste management (Nilsson, Pembe, Urasa, \& Darj, 2013). The management of the hospital waste is a neglected topic in many developing countries (Gupta \& Gupta, 2016). 
Prevalence of blood borne pathogens in developing countries is high; In a 2 years and 5 month prospective study conducted among the voluntarily reported exposed HCWs of the APEX trauma centre, Authors found that doctors have the highest exposure $(129,36.2 \%)$, nurses $(52,14.6 \%)$, before the hospital waste disposal staff with 7.6\% (Rajkumari et al., 2014). In the world, 70\% of infected people live in sub-Saharan Africa, but only $4 \%$ cases are reported from this region (Bekele, Gebremariam, Kaso, \& Ahmed, 2015).

In Cameroon, the policy concerning the prevention and care of AEB is not yet well defined in certain hospital. Hospital waste is a potential health hazard to the health workers and there is an underreporting of accidental Blood injuries (Nouetchognou, Ateudjieu, Jemea, \& Mbanya, 2016). The out-of- pocket is the main health financing method and the escalation of health care cost is a crisis. This situation affects the Healthcare provider in a general context of low resources. There are no national recommendations or vaccination program against HBV for HCWs and $60.7 \%$ of HCWs have experienced at least one episode of AEB for a one year period (Mbanya et al., 2010). There is a good awareness of the endemicity and consequences of the Hepatitis B in the country. A recent governmental measure was taken to reduce the treatment cost of the Hepatitis B delta and the Hepatitis C genotype 1 and $4 \mathrm{C}$, as reference to the Ministry of Public Health note $\mathrm{N}^{\circ}: 166 / \mathrm{C} / \mathrm{TE}$ of the $29^{\text {th }} \mathrm{July}$ 2016 for the availability and the official tarification of different treatment protocols of the hepatitis B and $\mathrm{C}$.

Vaccination of HCWs against HBV is a standard practice in many countries, but is often not implemented in poor-resource settings; In a tertiary hospital in Tanzania, only $77,1 \%$ of Healthcare workers who received a full vaccination course had an anti-Hbs titer $\geq 10 \mathrm{ml} / \mathrm{u}$ (Mueller et al., 2015). In the context of poverty, we aim to describe the implementation level of the international recommendations in an operational hospital and draw some recommendations for the better quality of health services to be provided to the health care personnel in the Biyem-Assi District hospital.

\section{Methode}

\section{Study type}

We carried out a cross-sectional hospital-based study conducted in the Biyem-assi District Hospital (BDH) from the 6th September to the 20th October 2016. It was cheap and less time consuming.

\section{Study population}

The study population consisted of health-care workers who are in contact with patients, or potentially exposed to body fluids from patients during their jobs. Among the total of 168 health personnel including 24 Medical Doctors, all those who accepted in each service and each groups of Healthcare workers were recruited. Staffs from administrative services, pharmacists and drivers were not included.

\section{Study setting}

The study was conducted at the Biyem-Assi District Hospital, a referral hospital at the operational level of the health pyramid.

\section{Sampling frame}

We used the Healthcare Workers list of the personnel in the secretariat of the director as a sampling frame.

\section{Sampling procedure}

We used a convenience sampling design in all the different health care workers groups (Medical doctors, Nurses, Laboratory technicians, assistants, medical or nurse students), assigned in different services that receive and take care of patients (Pediatric, Internal Medicine, Surgery, Emergency, Hygiene and sanitation, Laboratory, Gynecology and Maternity, Stomatology) . In each service, we received all consenting staff who accepted to participate in our study without any discrimination. 


\section{Data collection}

We first consulted the register for Occupational Injuries. Secondly, a pretested and anonymous questionnaire with closed and open-ended questions was prepared for the purpose of the study. It had 16 questions, including those about demographic characteristics (service, age, gender, occupation, length of employment), specific questions on the knowledge about AEB, diseases that may occur following to an AEB, the health insurance, as well as measures taken after the accident. In addition, the questionnaire was designed to obtain information on vaccination status for hepatitis $\mathrm{B}$. The questionnaires were pre-tested for validity, meaning, comprehension of questions with 05 sampled health workers of the International Immunization center of Yaoundé, and appropriate modifications made. The questionnaire was anonymous and self-administrated.

\section{Data analysis}

Statistical analyzes were performed with EPI-INFO 7.1.1.14 and MS Excel. Quantitative data were presented in percentage. In the register, we evaluated the proportion of the different mechanisms involved in AEB (percutaneous injury or splash). Then we evaluated the proportion of victims who have benefited from a post exposure prophylaxis and serological follow-up. A simple descriptive analysis was performed to estimate proportions of gender, occupational categories and number of years of service. In addition, we determined the proportion of vaccinated personals against HBV amongst the healthcare workers, and the number of personnel who have a health insurance.

\section{Ethical approval}

Written informed consent was sought prior to the inclusion in the study. As a hospital -based study, we also obtained an administrative authorization from the Director of the hospital to carry out the study.

\section{Results}

The presentation of our results was done with tables and figures.

\section{Reported cases of AEB from 2014 to 2016}

A total of 6 cases were reported in the register from March 2014 to July 2016. Concerning their function, it was variable, there was one medical student, but no Medical doctor declared the event in this period. Concerning the services, all were concerned. The mean age of the victims was 32.5 years. Most of them were female 5 over $6(83.33 \%)$. All of them were injured through the syringe- prick. All the $6(100 \%)$ patients' sources were HIV positive. All the 6 victims were wearing gloves during the event, 2 over 6 patients source declared not vaccinated against hepatitis B, 3 over 6 healthcare workers declared not vaccinated against the hepatitis $\mathrm{B}$, and 3 others were unknown.

\section{Post - exposure prophylaxis (PEP) according to the guidelines}

All the 6 patients sources were tested HIV positive, the $6 \mathrm{HCWs}$ victims were tested Negative and they were all on the PEP for one month with a good regimen of Anti-retroviral treatment (Tenofovir, Lamivudine and Efavirenz). No control of 1 month, 6 month, or 1 year were registered either for the HIV, Hepatitis B or the Hepatitis C. No titer of Anti-HBs was found in the register to confirm or to infirm the real protection of the HCW against the hepatitis B.

\section{Socio-Demographic characteristics of the survey's respondents}

Among the 168 Healthcare workers, 100 were contacted to take part of the study, giving the recruitment rate of 59.52\%. 43 accepted to participate in the study, giving the response rate of $43 \%$. Our sample was representative to all the HCWS of the Biyem-assi District Hospital in term of the function and service (Table 1). The mean age was 34.51 years; with the minimum of 20 years and the maximum of 54 years. The median of the number of years at service was 6 IQR [2.5 - 9]. The majority of participants were female $(83.72 \%)$, against $16.28 \%$ of male. The table1 is the summary of the participant's characteristics. 
DOI: $10.21522 /$ TIJPH.2013.05.04.Art029

ISSN: $2520-3134$

\section{Concerning the experience of the healthcare workers}

$36(83.72 \%)$ participants had good knowledge of the AEB, but 5 (11.62\%) did not (Table 1). 11 participants (25.58\%) declared to have experience an AEB the last 2 years (table 2).

\section{About the proportion of participants vaccinated against the hepatitis $B$}

$21(48.84 \%) \mathrm{HCW}$ were not vaccinated at the moment of our study, and 17 (39.53\%) declared being vaccinated against Hepatitis B (table 3).

\section{Health cost of the survey's population}

$83.72 \%$ of the participants do not have any Health insurance (figure3). They practiced mostly the Out-of-pocket to finance their health (figure 1).

\section{Discussion}

This study carried was a hospital based study, we performed a non-probability sample design and the number of participant is not statistically projectable in the city of Yaoundé (Cameroon). There was insufficient information concerning the reporting of injuries.

We aimed to describe the reporting cases, and assess the management quality according to the guidelines prescribed. The results showed an under reporting of cases. Most participants are female; this is the normal repartition of personnel. $36(83.72 \%)$ participants had good knowledge of the AEB, but $5(11.62 \%)$ did not. $21(60.47 \%) \mathrm{HCW}$ were not vaccinated at the moment of our study, and 17 (39.53\%) declared being vaccinated against Hepatitis B. 36 (83.72\%) participants had good knowledge of the AEB, but $5(11.62 \%)$ did not. 21 (48.84\%) have not received or completed their vaccination against Hepatitis B. $83.72 \%$ of the participants do not have any Health insurance.

\section{In the register}

It is appreciable to see the effort of the medical team to keep this register filled. This is different from what was described in the Yaounde central hospital in 2002, in the YUTH in 2013, where no registers were found to collect information about $\mathrm{AEB}$, meaning that there is a progressive change in attitude about the declaration of AEB.

Only the cases with HIV positive source were declared, this probably means that there were no reported cases with patient source HIV negative, this was the same in a study conducted in 2014 where there was a high rate of under reporting in the primary health care setting mostly $(82.0 \%$ of cases were not reported) due to lack of time (Mbah, 2014). No medical doctor declared an AEB for 2 years, this was also seen in the study conducted in the South Africa where Doctors did not report their injuries compared to nurses and the main reason given was the lack of time. This can also be explained by their good awareness and did not need to consult.

According to the guidelines, there is an underreporting of information about the Hepatitis test of the patient's source and the victims, no antibodies (Ac-Hbs) titer to control the real protection of the vaccinated HCWs victims and no control HIV tests after the PEP (1 month, 3months or 6months ), this would have reflected the outcome of the victims. This is different from what was described in a public clinic in Hong Kong, where drug-related adverse events were encountered in 88,6\%. And after a follow-up period of 6 months or ( 1 years for those who had taken HIV PEP), control tests were done to check for HIV, hepatitis B or C infection. .

\section{About the survey}

$83,72 \%$ of the participants have good awareness about the AEB, contrary to what was $70.6 \%$ found in the Yaoundé central hospital (Etounou Akono \& al, 2009) This good evolution can be explained by the sensitization made everywhere about the high transmission rate of the hepatitis compared to the HIV virus, and the promotion of the Immunization.

In our study, $21(48.84 \%)$ participants have not received or completed their vaccination against Hepatitis B. Mueller and col. found $20.2 \%$ of unvaccinated HCWs in a tertiary Tanzania hospital in 2015. It is less than $44 \%$ found among HCWs in the Yaoundé University Teaching hospital (Noubiap, Nansseu, Kengne, Tchokfe Ndoula, \& Agyingi, 2013) It was also described a prevalence of $5.6 \%$ of 
hepatitis B among medical and pharmacy students in the University of Douala with $82.4 \%$ of students unvaccinated against hepatitis B (Noubiap et al., 2013) and also experienced only 20 out of 111 (18\%) medical students vaccinated among medical students in the Douala University. This difference can be explained by our little sample size compared to what was used in YUH and in the University of Douala (Eloumou B., Noah N, \& Ngaba, 2014)

$83.72 \%$ of the participants do not have any Health insurance. This can be explained by the lack of money (Noubiap et al., 2013). This is similar to what was found among medical students; Over 111 medical students recruited in Cameroon only $20(18 \%)$ were vaccinated. It is really difficult for Healthcare worker to finance the immunization when it is not mandatory. Vaccines are expensive, only the first category of vaccines (for the expanded vaccination program) is free of charge. We appreciated the effort of the Ministry of Public health who regulated recently the cost of the Hepatitis $\mathrm{B}$ and Hepatitis $\mathrm{C}$ to allow many people to have access to the treatment.

\section{Conclusion}

There is little information on the outcome of the occupational injuries in the BDH. Strong regulations and efficient hospital organizations of health services are urgent to protect the healthcare personnel, and to limit complications for those suffering for occupational diseases. Strong policy is necessary for mandatory Vaccination of Healthcare workers against the Hepatitis B. To do this, we propose some recommendations for example to organize at the ministry level some amount of money per covered employee per month or per year at least for the prevention and control of the occupational diseases, to organize annually, mandatory education sessions for more adherences to infection control procedures and timely post-exposure management for healthier professionals, to organize low -cost screening tests, vaccination campaign against Hepatitis B, control of titer and complications for Healthcare personnel in the $\mathrm{BDH}$, to finance a Cohort study in a referral Clinic for therapeutic prevention of $\mathrm{HBV}, \mathrm{HCV}$, and $\mathrm{HIV}$ infection for Healthcare personnel in order to plan annually strategic actions.

\section{Tables and figures}

Table 1. Socio-demographic characteristics of the participants

\begin{tabular}{|l|l|l|}
\hline Variable & $\mathbf{N} \mathbf{( 4 3 )}$ & Percentage (\%) \\
\hline Service represented & & \\
\hline Hygiene and Sanitation & 06 & 13.95 \\
\hline Surgery & 05 & 11.63 \\
\hline Internal Medicine & 04 & 09.30 \\
\hline Gynaecology & 04 & 09.30 \\
\hline Laboratory & 07 & 16.28 \\
\hline Pediatric & 05 & 11.63 \\
\hline Stomatology & 10 & 23.25 \\
\hline Emergency & 02 & 04.66 \\
\hline sex & & \\
\hline Female & 36 & 83.72 \\
\hline Male & 07 & 16.28 \\
\hline Function & & \\
\hline Hygienist agent & 06 & 14.99 \\
\hline Nurse & 16 & 38.10 \\
\hline Laboratory technician & 04 & 09.52 \\
\hline Other technician & 02 & 04.76 \\
\hline Medical Student & 11 & 26.19 \\
\hline Medical Doctor & 03 & 07.14 \\
\hline Marital Status & & \\
\hline Single & 17 & 40.48 \\
\hline Married & 57.14 & 57.14 \\
\hline Widow & 1 & 2.38 \\
\hline
\end{tabular}


DOI: $10.21522 /$ TIJPH.2013.05.04.Art029

ISSN: $2520-3134$

Table 2. Proportion of participants who experienced an AEB

\begin{tabular}{|l|l|l|}
\hline $\begin{array}{l}\text { Victims of AEB } \\
\text { during past 2 years }\end{array}$ & N (43) & Percentage (\%) \\
\hline Yes & 11 & 25.58 \\
No & 27 & 62.79 \\
Missing & 05 & 11.63 \\
Total & 43 & 100 \\
\hline
\end{tabular}

Table 3. Proportion of participants vaccinated against the hepatitis B

\begin{tabular}{|l|l|l|}
\hline $\begin{array}{l}\text { Vaccination } \\
\text { Against } \\
\text { Hepatitis B }\end{array}$ & Frequency & Percentage \\
\hline No & 21 & 48.84 \\
Yes & 17 & 39.53 \\
Missing & 05 & 11.63 \\
Total & 43 & 100 \\
\hline
\end{tabular}

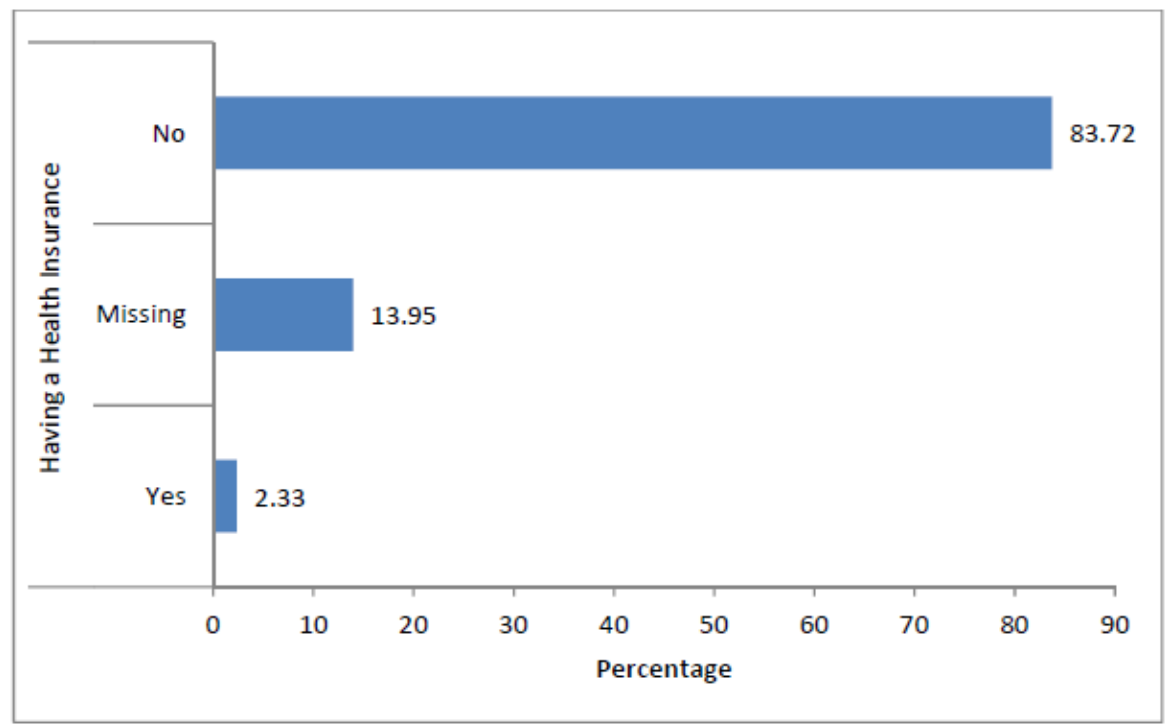

Figure 1. Proportion of participants having health insurance

\section{Acknowledgements}

We thank the Healthcare personnel who helped us to collect these informations in the registers, and we are grateful to the director of the District hospital of Biyem-assi who encouraged us to conduct these studies for the better quality of health services. 


\section{References}

[1].Bekele, T., Gebremariam, A., Kaso, M., \& Ahmed, K. (2015). Attitude, reporting behavour and management practice of occupational needle stick and sharps injuries among hospital healthcare workers in Bale zone, Southeast Ethiopia: a cross-sectional study. Journal of Occupational Medicine and Toxicology (London, England), 10, 42. https://doi.org/10.1186/s12995-015-0085-2

[2].Eloumou B., S., Noah N, D., \& Ngaba, G. P. (2014). Vaccinal status against Hepatitis B and carying the AgHBS among Medical and pharmacy students in the University of Douala.

[3].Etounou Akono, T., \& al. (2009). Connaissancs Attitudes et Pratiques du personnel de santé aux acccidents d'exposition au sang à la maternité de l'hopital central de Yaoundé. Université de Yaouné I, Yaoundé.

[4].Gupta, E., \& Gupta, A. (2016). Blood-borne viruses and health care workers: A neglected entity! Indian Journal of Medical Microbiology, 34(2), 137-138. https://doi.org/10.4103/0255-0857.176854

[5].Jain, M., Sabharwal, E. R., \& Srivastava, D. (2016). Practices of Health Care Personnel Regarding Occupational Exposure. Journal of Clinical and Diagnostic Research: JCDR, 10(11), DC14-DC17. https://doi.org/10.7860/JCDR/2016/20934.8893

[6].Mbah, C. C. (2014). Reporting of accidental occupational exposure to Blood and Body Fluids by Doctors and Nurses in the Public Primary Health Care setting of sub district F of Johannesburg Metropolitan district. University of Wiwatersrand, Johannersburg.

[7].Mbanya, D., Ateudjieu, J., Tagny, C. T., Moudourou, S., Lobe, M. M., \& Kaptue, L. (2010). Risk Factors for Transmission of HIV in a Hospital Environment of Yaoundé, Cameroon. International Journal of Environmental Research and Public Health, 7(5), 2085-2100. https://doi.org/10.3390/ijerph7052085

[8].Mueller, A., Stoetter, L., Kalluvya, S., Stich, A., Majinge, C., Weissbrich, B., \& Kasang, C. (2015). Prevalence of hepatitis B virus infection among health care workers in a tertiary hospital in Tanzania. BMC Infectious Diseases, 15, 386. https://doi.org/10.1186/s12879-015-1129-z

[9].Nilsson, J., Pembe, A. B., Urasa, M., \& Darj, E. (2013). Safe injections and waste management among healthcare workers at a regional hospital in northern Tanzania. Tanzania Journal of Health Research, 15(1), 6470.

[10]. Noubiap, J. J. N., Nansseu, J. R. N., Kengne, K. K., Tchokfe Ndoula, S., \& Agyingi, L. A. (2013). Occupational exposure to blood, hepatitis B vaccine knowledge and uptake among medical students in Cameroon. BMC Medical Education, 13, 148. https://doi.org/10.1186/1472-6920-13-148

[11]. Nouetchognou, J. S., Ateudjieu, J., Jemea, B., \& Mbanya, D. (2016). Accidental exposures to blood and body fluids among health care workers in a Referral Hospital of Cameroon. BMC Research Notes, 9. https://doi.org/10.1186/s13104-016-1923-8

[12]. Puro, V., De Carli, G., Cicalini, S., Soldani, F., Balslev, U., Begovac, J., ... European Occupational PostExposure Prophylaxis Study Group. (2005). European recommendations for the management of healthcare workers occupationally exposed to hepatitis B virus and hepatitis C virus. Euro Surveillance: Bulletin Européen Sur Les Maladies Transmissibles = European Communicable Disease Bulletin, 10(10), 260-264.

[13]. Rajkumari, N., Thanbuana, B. T., John, N. V., Gunjiyal, J., Mathur, P., \& Misra, M. C. (2014). A prospective look at the burden of sharps injuries and splashes among trauma health care workers in developing countries: true picture or tip of iceberg. Injury, 45(9), 1470-1478. https://doi.org/10.1016/j.injury.2014.03.001

[14]. Streefland, P. H. (2001). Public doubts about vaccination safety and resistance against vaccination. Health Policy (Amsterdam, Netherlands), 55(3), 159-172.

[15]. World Health Organization. (2012). International travel and health. 